\title{
Progress of Ontario's Family Health Team Model: A Patient-Centered Medical Home
}

\author{
Walter W. Rosser, $M D^{1}$ \\ Jack M. Colwill, $M D^{2}$ \\ Jan Kasperski, RN, MHSc ${ }^{2}$ \\ Lynn Wilson, $M D^{3,4}$
}

'Department of Family Medicine, Queen's University School of Medicine, Kingston, Ontario, Canada

${ }^{2}$ Department of Family and Community Medicine, University of Missouri, Columbia, School of Medicine, Columbia, Missouri

${ }^{3}$ Ontario College of Family Physicians, Toronto, Ontario, Canada

${ }^{4}$ Department of Family Medicine, University of Toronto School of Medicine, Toronto, Ontario, Canada

Conflicts of interest: authors report none.

\section{CORRESPONDING AUTHOR}

Jack M. Colwill, MD

Department of Family

and Community Medicine

M224 Medical Sciences Bldg

School of Medicine

University of Missouri, Columbia

Columbia, MO, 65212

colwillj@health.missouri.edu

\begin{abstract}
Ontario's Family Health Team (FHT) model, implemented in 2005, may be North America's largest example of a patient-centered medical home. The model, based on multidisciplinary teams and an innovative incentive-based funding system, has been developed primarily from fee-for-service primary care practices. Nearly 2 million Ontarians are served by 170 FHTs. Preliminary observations suggest high satisfaction among patients, higher income and more gratification for family physicians, and trends for more medical students to select careers in family medicine. Popular demand is resulting in expansion to $200 \mathrm{FHTs}$. We describe the development, implementation, reimbursement plan, and current status of this multidisciplinary model, relating it to the principles of the patient-centered medical home. We also identify its potential to provide an understanding of many aspects of primary care.
\end{abstract}

Ann Fam Med 2011;9:165-171. doi:10.1370/afm.1228.

\section{INTRODUCTION}

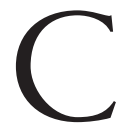
anada, as does the United States, faces a crisis in primary care. In response, a number of primary care reform models have been developed across Canada during the past decade. Of these models, Ontario's Family Health Team (FHT) model, ${ }^{1}$ begun in 2005, most closely mirrors the "Principles of the Patient-Centered Medical Home" as endorsed by the American Academy of Family Physicians, the American College of Physicians, the American Academy of Pediatrics, and the American Osteopathic Association. ${ }^{2}$ We briefly described this model in an online publication in the New England Journal of Medicine ${ }^{3}$ and now provide a more complete description of FHTs' implementation, how FHTs achieve the joint principles of the patient-centered medical home, ${ }^{2}$ and how the payment model provides incentives to achieve patient care goals. We further provide early findings of their potential impact and discuss applicability of the model for the United States.

Little information exists about wide implementation of medical homes or of their efficacy in improving patient and physician satisfaction, increasing efficiency, reducing costs, and improving outcomes. We believe a description of the FHT model provides useful information for the United States as it moves toward primary care reform.

\section{IMPLEMENTATION OF THE FHT MODEL IN ONTARIO}

In 1969 Canada adopted a universal first dollar health insurance program funded jointly by the provinces and the federal government. Each province assumed responsibility for its own health care system according to national guidelines. During its initial years, Ontario's health care system seemed well-funded and worked to the satisfaction of most Ontarians. By the mid 1980s, however, family physicians, the only primary care physician specialty in Canada, began to struggle to meet demands of their practices, and physician shortages began to appear. Most physicians were in solo or small-group fee-for-service practices. Physicians felt pressured 
to provide more visits in the face of costs rising and incomes static or falling. Many physicians began to express concerns about the quality of the care they were delivering and about the impact of the pressures on their personal lives. ${ }^{4}$ Some narrowed the scope of their practices and others increased referrals to specialists, feeling too overloaded to care for the more complex patients. With specialization becoming more attractive, the percentage of Ontario graduates entering family medicine fell to $24 \%$ in 2004 , even though family physicians have traditionally comprised one-half of all Canadian physicians. This decline posed a real threat for Canada's health care system.

The chairs of the 5 university departments of family medicine were concerned that fee-for -service payment aggravated problems by providing perverse incentives which rewarded high-volume practices at the expense of person-centered care-the model used in their teaching programs. Their 1994 article reviewed international systems of family practice. ${ }^{5}$ In 1996 a governmentappointed committee, the Provincial Coordinating Committee on Community and Academic Health Science Center Relations (PCCAR), identified a "basket of services" that should be provided by the "ideal" family practice (Table 1). ${ }^{6}$ (A very similar basket was subsequently described in the Future of Family Medicine Report in the United States. ${ }^{7}$ ) The PCCAR was concerned that overloaded family physicians were limiting their services and unnecessarily referring patients away for care-thus contributing to fragmentation and costs of care.

In 1999, the provincial Chapter of the College of Family Physicians published a policy document outlining directions for family medicine, and Healthcare Papers featured the College's vision of a patient-centered health home. ${ }^{8,9}$ Then the 2004 provincial elections brought a new political party to power promising that every resident would have a family doctor.

This new provincial government introduced FHTs to Ontario's health care landscape. ${ }^{1}$ FHTs evolved from several earlier Ontario pilots, among which are Community Health Centers (CHCs), Family Health Networks (FHNs), and Family Health Groups (FHGs). ${ }^{10}$ CHCs, originating in 1980, are more likely to serve rural, low-income, or minority populations. Physicians are reimbursed by salary, and practices are likely to have multidisciplinary teams. FHNs, initiated in 2001, serve general populations and pay physicians on a blended funding formula based on capitation with additional financial incentives. FHGs, begun in 2003, reimburse physicians on a fee-for-service basis with bonuses. Both FHNs and FHGs give physicians responsibility for a panel of patients and have relatively few interdisciplinary care clinicians. The new FHT model basically adds multidisciplinary clinicians to the
FHN model to assist the family physician and expand the scope of the practice. Sixty-eight percent of Ontario's population is now registered in one of these models, whereas most primary care for other provinces continues in independent fee-for-service practices.

Today, the number of FHTs exceed 170, with 1,500 physicians providing care for nearly 2 million persons. Each family physician is expected to have a panel of approximately 1,400 persons, and panel sizes are expanded as multidisciplinary team members are added.

The FHT model is flexible and based on community needs, with no 2 FHTs the same. The desired practice size comprises at least 7 family physicians and a multidisciplinary team so that the practice can facilitate a wide range of services and 7-day-a-week access to care. Rural FHTs may extend over many kilometers with 1 or 2 physicians in each village.

Physicians sign an agreement with the government to provide a broad basket of services (Table 1), and they accept a blended model of funding, including capitation, fees for services, bonuses for achieving prevention targets, and special payments to expand the scope of care to incorporate prenatal and intrapartum care, inpatient care, home visits, and palliative care. They also receive support for nonphysician professionals, as well as an electronic medical record that practices select from 7 different software systems meeting provincial standards.

\section{FHT MODEL AND THE JOINT PRINCIPLES OF A PATIENT-CENTERED MEDICAL HOME}

The joint principles of a patient-centered medical home are displayed in Table 2. ${ }^{2}$ These principles have been developed and promoted by the Patient-Centered Primary Care Collaborative, a group comprised of the

\section{Table 1. PCCAR Basket of Services}

Advocacy for the patient in the system

Appropriate interventions for episodic illness and injuries Diagnosis and initial/ongoing treatment of chronic disease Primary mental healthcare including psychosocial counseling Primary reproductive care

Care of the majority of illness (in conjunction with consultation, if required)

Supportive care in hospital, home or community care facilities Health assessment

Clinical evidence-based illness prevention and health promotion Education and support for self-care

Support for the terminally ill

Arrangements for response to urgent problems 24 hours a day, 7 days a week

Service coordination and referral

Coordination and access to rehabilitation

From the Provincial Coordinating Committee on Community and Academic Health Science Center Relations (PCCAR). ${ }^{6}$ 


\section{Table 2. Joint Principles of the Patient-Centered Medical Home}

1. Personal physician - each patient has an ongoing relationship with a personal physician trained to provide first contact, continuous and comprehensive care

2. Physician-directed medical practice - the personal physician leads a team of individuals at the practice level who collectively take responsibility for the ongoing care of patients

3. Whole-person orientation - the personal physician is responsible for providing for all the patient's health care needs or taking responsibility for appropriately arranging care with other qualified professionals. This includes care for all stages of life; acute care; chronic care; preventive services; and end of life care...

4. Care is coordinated and/or integrated across all elements of the complex health care system and the patient's community

5. Quality and safety are hallmarks of the medical home...

6. Enhanced access to care is available through systems such as open scheduling, expanded hours and new options for communication ...

7. Payment appropriately recognizes the added value provided to patients who have a patient-centered medical home...

From the Patient-Centered Primary Care Collaborative. ${ }^{2}$

American Academy of Family Physicians, the American Academy of Pediatrics, the American College of Physicians, and the American Osteopathic Association. We describe how the FHT model achieves these goals.

\section{Personal Physician}

Patients who want to receive care from a FHT must register formally within the insurance system and select a physician at a practice. This physician is responsible for providing each patient with the basket of services, including coordinating care both within the practice and elsewhere in the system. Individual physicians might not deliver every service, but the group must be so organized to provide them. Many FHTs have a minor procedure clinic, an obstetric call group, a hospital working group, and a group that oversees the care of patients in their homes and in senior facilities. The central role delegated to the person's family physician and his or her team fosters patients' perceptions that they are patients of the physician and team rather than patients of the clinic.

\section{Physician-Directed Medical Practice}

The ultimate responsibility for clinical care lies with the physician. Physicians are encouraged to develop multidisciplinary teams, thus expanding the scope of services and lightening the physician's load. The number of other health care clinicians funded by the Ministry is based on a formula: 1 nurse practitioner for every 4,000 registered patients with expected expansion of the practice by 800 patients; 1 registered nurse for every 4,000 patients with 400 patients added 1 pharmacist for every 10,000 patients, and so on. Thus a group of 7 family physicians would be expected to have a panel of 9,800 patients and might add 2 nurse practitioners, 2 registered nurses, and a pharmacist while increasing the practice size to 12,200 . Social workers, psychologists, health educators, occupational therapists, and other support personnel may also be included in the team.

Within FHTs, physicians set medical practice policies. The FHTs themselves are governed by boards responsible to the Ministry for identifying and meeting needs of the practice population, managing resources, and monitoring patient satisfaction and quality of care. There are 3 types of boards. The most common type is provider based, controlled by physicians and other practice members. The boards of community-sponsored FHTs, drawn from the community, usually represent the needs of special groups within the community. Mixed governance boards have provider, community, and organizational representation from hospitals, universities, etc.

\section{Whole-Person Orientation}

The basket of services (Table 1) defines the broad scope of whole-person medicine delivered by the FHT team. In essence, the FHT serves as the site of most patient care. The personal physician provides much of the care and sees that appropriate services are provided. Trust between patient and physician forms the basis for trust in the team.

\section{Coordinated or Integrated Care}

Electronic health records (EHRs), corridor consultations, and team meetings help coordinate care among team members. The EHR captures activities of every patient with each clinician and every contact with the practice, including telephone or e-mail, thus providing the infrastructure for assessment of outcomes.

The role of the specialist, who historically has functioned as a consultant, rarely seeing a patient without referral, facilitates the coordinating role of the family physician. Thus the respective roles of family physician and specialist are less ambiguous than in the United States. In many FHTs family physicians increasingly share with specialists the care of patients who have chronic disorders rather than refer them elsewhere for care. Funding is available for on-site consultations by psychiatrists, internists, or pediatricians in collaboration with FHT team members. Specialists are reimbursed for these consultations on a fee-per-session basis.

Most family physicians remain involved in their patients' care regardless of whether a patient is in the hospital, at home, or in a nursing home. Family physicians may serve as the attending physician for hospitalized patients or provide concurrent care when patients are hospitalized by a specialist. Hospitals have difficulty discharging patients who do not have a family doctor, and FHTs are often identified for patients who require follow-up.

Although care coordination is not perfect, the FHT 
structure and the use of EHRs facilitate coordination. Few assessments thus far test the best strategies for achieving optimal outcomes, however. The current comprehensive Ontario Diabetes Strategy is developing a model of integrated, coordinated care that may be applicable to other FHT chronic disease management strategies. ${ }^{11}$

\section{Quality and Safety}

Ontario has developed a system for the assessment of quality and safety in FHTs. At the provincial level, the Ontario Health Quality Council uses billing data to assess quality in the entire health care system and produces annual reports on strengths and weaknesses of primary and other health care in Ontario. The Ontario Association of Family Health Teams, comprised of FHT leaders, recommends strategies to address quality issues raised by the Quality Council. Each FHT board, using the extensive data generated from its EHR, is responsible for auditing its performance and implementing strategies to improve care. An evaluation program (The Quality in Family Practice), developed by McMaster University and the Ontario College of Family Physicians, provides practices with a book of tools for improving quality and safety. ${ }^{12}$ There is no certifying organization such as that provided by the National Committee for Quality Assurance (NCQA) in the United States. Data from the billing system documents the breadth of services and provides data for quality assessment.

In the typical FHT, the EHR provides current information collected from team members, as well as prompts for evidence-based prevention and clinical support tools. In most FHTs, the pharmacist reviews medications for patients receiving 4 or more drugs, and the EHR flags potential drug interactions. Flow sheets remind physicians of developmental milestones for children and alert team members to inspect feet and eyes and monitor glycated hemoglobin levels in patients with diabetes. Nurses and pharmacists visit patients in their homes to determine whether medications are being taken and whether management strategies can be enhanced. Patient education tool kits assist with patient self-management.

\section{Enhanced Access}

The Ministry agreement requires each FHT to provide 3 -hour evening and weekend clinics for walk-in and scheduled patients, as well as an after-hours on-call system. During after-hours service a province-wide nurse telephone triage system provides protocol-driven guidance and advice for patients, thereby reducing telephone calls to physicians by $80 \%$. FHT physicians provide backup support to the nurses and receive reports on each patient the following morning. Many practices have established a same-day appointment system for their patients. A physician does not receive the monthly access bonus when his or her patient seeks care in other parts of the system for problems that are not emergencies. Payment for patients who repeatedly use the system inappropriately may be changed from capitation to fee for service.

The government's first priority in establishing FHTs was to increase access to primary care. Physicians therefore receive between Can $\$ 100$ and Can $\$ 300$ bonus for each new patient accepted, depending upon the complexity of the patient's care.

\section{Payment Reform}

Physician income is derived from a blended funding model that combines capitation, fees for services, and bonuses. This reimbursement strategy provides incentives for patient-centered care as well as populationoriented preventive care. Capitation levels are based on the province's previous fee-for-service experience and divided into 38 levels by age and sex. The initial average annual capitation rate was Can $\$ 124.64$ per year-ranging from Can $\$ 58.58$ for a male patient aged 15 to 19 years to Can $\$ 444.96$ for a female patient aged 90 years. Additional annual payments are provided for patients with chronic diseases, such as diabetes (Can $\$ 60$ per year), serious mental disease (Can $\$ 60)$, and heart failure (Can\$125).

Fee income provides incentives for physicians to increase desired services. Thus physicians receive additional fees for visits by patients who are younger than 1 year and older than 75 years. They also receive fees for providing hospital care and special annual payments for achieving volume targets for intrapartum care, prenatal care, home visits, palliative care, and office procedures.

Progressive population-based bonuses provide incentives for preventive services, such as mammograms, Papanicolaou smears, influenza immunization, and colorectal cancer screening. The physician receives Can $\$ 2,200$ if $50 \%$ of patients older than 50 years have fecal occult blood testing for colorectal cancer and Can $\$ 4,400$ if $70 \%$ are screened. Codes for each preventive service are submitted to the billing agency to determine the percentage of registered patents receiving the preventive procedure. Physicians may bill for the costs of sending reminders to support contacting patients about preventive services.

FHT physicians receive approximately $60 \%$ of their income from capitation and $40 \%$ from fee-for-service and bonuses. FHTs must provide parallel fee-forservice bills for every visit. Although time consuming, this shadow billing is key to evaluation of the reformed payment system.

Conversion from a fee-for-service practice to a FHT appears to become viable when about $60 \%$ of patients 
have converted to the FHT model. During the first year physicians may elect to receive monthly stipends equivalent to their previous fee-for-service billing. Once FHT billing exceeds the value of fee-for-service billing, the individual physician can convert to FHT funding. FHT physicians also receive an annual continuing medical education incentive (Can $\$ 100$ per credit hour and up to 24 hours of continuing education).

A central feature of funding is that the Ministry provides the salaries for interdisciplinary team members and funding for EHRs. Without this support, physicians would have less incentive to expand their practices. Each FHT governing board decides which professionals to hire based on patient needs.

\section{DISCUSSION}

Over a 5-year period Ontario has implemented 170 FHTs, serving almost 2 million people, and is currently expanding to 200 FHTs. FHT's probably would not have been implemented without a previous decade of effort by family physicians. The Ministry has now made impressive commitments to primary care at a time when a shortage of specialists is also a major concern. The FHT model increases access to primary care for Ontarians and addresses physicians' frustrations with practice. Panel sizes are smaller than in the fee-for-service sector of Canada and the United States, and interdisciplinary teams have potential to provide comprehensive care management for chronically ill patients. The reimbursement plan, which is weighted heavily on incentives and lightly on mandates, provides necessary incentives to expand preventive services and care management.

The FHT model provides an implied contract for both patients and physicians. Patients, by registering, accept the concepts behind the medical home, commit to care by the team, and assume responsibility for their own health. Physicians assume overall responsibility for care of their patient panel, both when members seek care and when they do not. If carried out as planned, more patients will have access to primary care ${ }_{i}$ mental health services will be integrated more effectively into primary care; and emergency departments will be utilized more appropriately. FHT physicians will share care with specialists and be more involved in decision making in the hospital, thus reducing duplication and fragmentation of care.

Because physician income is not primarily based on numbers of physician visits, practices are able to explore broader roles for team members, as well as use of telephone, e-mail, and group visits to enhance efficiency. The addition of other health professionals should enhance management of chronically ill and complex patients. Additional fee payments should promote well-child care, care of elderly patients, and care in the hospital, home, and nursing home. Bonuses foster population-based prevention goals. Integrated electronic medical records make enhanced communication possible. The incentives are designed to encourage physicians to provide preventive services and care management for chronically ill patients.

The FHT model is a work in progress, and studies are essential to assess the degree to which the above expectations actually occur. Undoubtedly, with experience, the model will be fine-tuned to enhance patient care goals.

The huge database obtained by the Ministry from billings by each FHT provides a remarkable research platform to test the hypotheses listed in the paragraphs above, as well as to test broader issues in primary care. Thus, outcomes of FHTs, with their interdisciplinary teams and blended payments, can be compared with those of fee-for-service FHGs, which have few interdisciplinary clinicians. The National Demonstration Project for patient-centered medical homes in the United States finds that family physicians in fee-for-service settings have been reluctant to delegate care to other team members when implementing medical homes. ${ }^{13}$ This should be different in FHTs, which receive the majority of their funding from capitation.

The Ministry of Health has contracted with the Conference Board of Canada to carry out the official evaluation of FHTs. This contract focuses primarily on the cost effectiveness of the system, but it also includes quality-of-care indicators, patient satisfaction, and physician and staff satisfaction. Initial reports are expected in 1 to 2 years.

We are aware of several other research projects involving FHTs, but to our knowledge, none have yet been published. Nevertheless, several studies evaluating earlier models provide clues for what may be anticipated with FHTs, with their blended payments and interdisciplinary clinician teams.

Sarma et al found that physicians in fee-for-service practices have the highest number of patient visits per week $k_{i}$ those in the blended payment FHN models have an intermediate numbers of visits per week; and those in salaried $\mathrm{CHCs}$ have the fewest visits per week. ${ }^{14}$ Green et al report that physicians in the FHN model with blended funding and few interdisciplinary clinicians have higher incomes and greater satisfaction with their practices than those in fee-for-service practices. ${ }^{15}$ The number of visits per month declined for physicians when they converted from independent fee-for-service practice to blended funding FHNs, whereas visits in FHGs funded by fee-for-service did not change. In a small unpublished survey, Green also found higher levels of patient satisfaction in FHNs than in fee-for-service models.

Glazier et al, using administrative data, found lower 
use of after-hours care and more emergency department visits by patients in FHNs (blended payment systems and few interdisciplinary clinicians) than by those in FHGs (fee-for-service payment and few interdisciplinary clinicians). ${ }^{16}$ Measures of continuity and comprehensiveness were similar. These observed differences seemed due to patient characteristics rather than the reimbursement model, because patients had similar utilization patterns before entering the FHN. Russell et al, evaluating disease management of 4 common chronic diseases, found best indicators of quality in CHCs (salary based, fewer physician visits per month, and larger numbers of interdisciplinary clinicians. $)^{17}$

Across all practice models the presence of nurse practitioners was positively associated with better disease management and negatively associated with practice size and numbers of visits per physician. ${ }^{17}$ Tu et al found better blood pressure control in FHNs compared with fee-for-service FHGs and salaried $\mathrm{CHC}$ practices in Ontario. ${ }^{18}$ They recognize that $\mathrm{CHCs}^{\prime}$ findings may be biased by the higher percentages of low-income patients and smokers.

Physician incomes in FHTs have risen approximately $40 \%$ since their introduction, bringing family physicians' incomes in FHTs to $80 \%$ of the average specialist. (In the United States, income of primary care physicians is about $50 \%$ that of specialists.) In 2004 the average net income (after expenses) of a physician with 1,400 patients was Can $\$ 180,000$. Annual income subsequently increased to Can $\$ 250,000$ for physicians in FHTs, whereas annual income in fee-forservice practices showed little increase. ${ }^{15}$ Since the last survey, physician income has further increased.

Most Ontario teaching practices are FHTs. Faculty emphasize patient-centered care in both undergraduate medical education and in family medicine residency programs, so learners put theory into action in the FHTs. Interestingly, the percentage of Ontario medical students entering family medicine increased from $25 \%$ in 2004 to $39 \%$ in 2009 and 2010, while in other Canadian provinces the percentage increased from $24 \%$ in 2004 to $29 \%$ in 2009 and $35 \%$ in $2010 .{ }^{19}$ Whether increases relate to the ferment in reforming primary care in Canada is unknown.

Ontario still faces a continuing shortage of family physicians. Government and academic family medicine departments are striving to increase the number of family medicine residents trained each year. Improvements in the practice environment and in incomes are attracting family physicians from other provinces and countries. Nevertheless, the goal that every person in Ontario have a family doctor has yet to be realized. The provincial government is committed to increasing the number of FHTs to 200, and there are many applicants

\section{Implementation in the United States}

Efforts to implement the medical home in the United States are ongoing, and some managed care organizations and integrated delivery systems already incorporate medical homes within their systems. ${ }^{20}$ We believe most primary care practices also attempt to provide comprehensive care, but they are hindered by a dysfunctional payment system that provides no incentive to follow up on a patient at home after an episode of heart failure or to remind a patient to schedule a mammogram.

Broad implementation, especially in smaller practices, is challenging. ${ }^{13,21}$ Groups must restructure their practices to facilitate preventive services, provide care management for chronically ill patients, and offer better access for all patients. Implementation requires an interdisciplinary team and an integrated EHR system, as well as physicians ready to delegate responsibility to team members and to implement an EHR, which is unlikely to occur without major payment reform. Some physicians will decide an urgent care clinic or a hospitalist practice is more attractive.

Unlike Ontario, US physician groups must contract with multiple insurers. It is unknown whether payers and insurers will make the necessary investments in primary care to make this possible. In markets with many insurers, cooperative efforts by insurers are needed to assure that a high percentage of patients in each physician's practice are covered. Insurers are capable of rapid change, as was illustrated by development of capitated systems in anticipation of Clinton's health care reform, but lessons from ill-fated gatekeeper plans cannot be forgotten. Patients must view their physician as their advocate in navigating the system rather than as their gatekeeper.

Many recognize the patient-centered medical home must be linked with other parts of the system to maximize quality and cost containment. ${ }^{22}$ Such linkages may be less of an issue in Ontario than in the United States, partly because of differences in the mix of primary care physicians and specialists. In Canada there are one third fewer physicians, $15 \%$ more primary care physicians, and only one-half as many specialists per capita. ${ }^{23,24}$ Overloaded Canadian specialists rarely see patients who are not referred and receive lower fees if they do. In contrast, in the United States, 70\% of patient visits to specialists are without physician referral, ${ }^{25}$ and higher payments for consultations are being eliminated by Medicare, thus reducing the incentive for specialists to focus on consultations. Accountable Care Organizations are seen by many in the United States as a necessary partner for the medical home in containing costs. ${ }^{22}$ Ontario, with development of FHTs and with its mix of generalists and specialists may achieve similar objectives. 
The United States, as does Canada, faces major shortages of primary care physicians for care of adults. If the current US primary care practice model continues as it is today, 44,000 additional family physicians and general internists would be needed in 2025 simply to maintain current numbers of visits for each adult as the population increases and ages. ${ }^{26}$ To achieve this goal would require an immediate increase of about 3,000 family medicine and general internal medicine graduates annually. An increase of this magnitude seems unlikely, but wide adoption of patient-centered medical homes could be part of the workforce solution by providing a desirable workplace for needed physicians, nurse practitioners, and physician assistants. Without workforce increases, primary care services will fall increasingly on emergency departments and specialists, who themselves may be overworked, less prepared, and less disposed to provide this breadth of services. Without change, the United States faces the likelihood of increased medical homelessness. ${ }^{27}$

The Ministry anticipates that its comprehensive patient-centered medical home model will expand primary care services in Ontario at a time of primary care physician shortage. We also hope that research will show the FHT model enhances patient access to higher quality, more comprehensive, and cost-effective care. It provides the type of practice many of us in primary care had hoped to have when we entered medical school. It should be part of the solution for health system reform for both Canada and the United States.

To read or post commentaries in response to this article, see it online at http://www.annfammed.org/cgi/content/full/9/2/165.

Key words: Primary health care; health care delivery; quality of health care; health policy; patient-centered care

Submitted February 22, 2010; submitted, revise, October 18, 2010; accepted November 29, 2010.

\section{References}

1. Government of Ontario, Canada. Ministry of Health and Long-Term Care. Family health teams. 2010. http://www.health.gov.on.ca/ transformation/fht/fht_mn.html. Accessed Jun 21, 2010.

2. American Academy of Family Physicians (AAFP), American Academy of Pediatrics (AAP), American College of Physicians (ACP), American Osteopathic Association (AOA). Joint principles of the Patient Centered Medical Home. Washington, DC: Patient-Centered Primary Care Collaborative. 2007. http://pcpcc.net/content/jointprinciples-patient-centered-medical-home. Accessed Sep 8, 2009.

3. Rosser WW, Colwill JM, Kasperski J, Wilson L. Patient-centered medical homes in Ontario. N Engl J Med. 2010;362(3):e7.

4. Canadian Medical Association. Strengthening the Foundation. The Role of the Physician in Primary Health Care in Canada. Ottawa: Canadian Medical Association;1994.

5. Forster J, Rosser W, Hennen B, McAuley R, Wilson R, Grogan M. New approach to primary medical care. Nine-point plan for a family practice service. Can Fam Physician. 1994;40:1523-1530.
6. Glynn P. Provincial Coordinating Committee on Community and Academic Health Science Centre Relations. New Directions in Primary Health Care. Toronto: Ministry of Health; 1996.

7. Martin JC, Avant RF, Bowman MA, et al; Future of Family Medicine Project Leadership Committee. The Future of Family Medicine: a collaborative project of the family medicine community. Ann Fam Med. 2004;2(Suppl 1):S3-S32.

8. Green LA. Rhetoric, reality and revolution in family practice and primary care. Healthc Pap. 1999;1(1):57-60, discussion 89-93.

9. Rosser WW, Kasperski J. Organizing primary care for an integrated system. Healthc Pap. 1999;1(1):5-21.

10. Muldoon L, Rowan MS, Geneau R, Hogg W, Coulson D. Models of primary care service delivery in Ontario: why such diversity? Healthc Manage Forum. 2006;19(4):18-23.

11. Government of Ontario, Canada. Stand up to diabetes [Web page]. 2009. http://www.health.gov.on.ca/en/ms/diabetes/en/. Accessed Sep 23, 2010

12. Quality in family practice [Web site]. Hamilton, Ontario: Department of Family Medicine, McMaster University. 2008. http://www .qualityinfamilypractice.com/. Accessed Sep 23, 2010.

13. Crabtree BF, Nutting PA, Miller WL, Stange KC, Stewart EE, Jaén CR. Summary of the National Demonstration Project and recommendations for the patient-centered medical home. Ann Fam Med. 2010;8(Suppl 1):S80-S90, S92.

14. Sarma S, Devlin RA, Hogg W. Physician's production of primary care in Ontario, Canada. Health Econ. 2010;19(1):14-30.

15. Green ME, Hogg W, Gray D, et al. Financial and work satisfaction: impacts of participation in primary care reform on physicians in ontario. Healthc Policy. 2009;5(2):e161-e176.

16. Glazier RH, Klein-Geltink J, Kopp A, Sibley LM. Capitation and enhanced fee-for-service models for primary care reform: a population-based evaluation. CMAJ. 2009;180(11):E72-E81.

17. Russell GM, Dahrouge S, Hogg W, Geneau R, Muldoon L, Tuna M. Managing chronic disease in ontario primary care: the impact of organizational factors. Ann Fam Med. 2009;7(4):309-318.

18. Tu K, Cauch-Dudek K, Chen Z. Comparison of primary care physician payment models in the management of hypertension. Can Fam Physician. 2009;55(7):719-727.

19. Reports \& Statistics R-1 Match Reports. Ottawa, ON: Canadian resident matching service. 2010. http://www.carms.ca/eng/operations _R1reports_e.shtml. Accessed Jan 8, 2010.

20. Reid RJ, Coleman K, Johnson EA, et al. The group health medical home at year two: cost savings, higher patient satisfaction, and less burnout for providers. Health Aff (Millwood). 2010;29(5):835-843.

21. Nutting PA, Miller WL, Crabtree BF, Jaén $C R$, Stewart EE, Stange KC. Initial lessons from the first national demonstration project on practice transformation to a patient-centered medical home. Ann Fam Med. 2009;7(3):254-260.

22. Rittenhouse DR, Shortell SM, Fisher ES. Primary care and accountable care-two essential elements of delivery-system reform. N Engl J Med. 2009;361(24):2301-2303.

23. Smart DR, ed. Physician Characteristics and Distribution in the US, 2009. Chicago, IL: American Medical Association; 2009.

24. Canadian Medical Association. Statistical information on Canadian physicians. Ottawa, Ontario: The Association; 2010. http://www. cma.ca/index.php?ci_id=16959\&la_id=1. Accessed Sep 23, 2010.

25. Valderas JM, Starfield B, Forrest CB, Sibbald B, Roland M. Ambulatory care provided by office-based specialists in the United States. Ann Fam Med. 2009;7(2):104-111.

26. Colwill JM, Cultice JM, Kruse RL. Will generalist physician supply meet demands of an increasing and aging population? Health Aff (Millwood). 2008;27(3):w232-w241.

27. Colwill JM. Narrative matters. A case of 'medical homelessness'. Health Aff (Millwood). 2010;29(5):1067-1070. 